\title{
Enhancing debate about the sexes
}

Is it good for there to be both males and females of our species? This question seems highly fanciful, and a long way from the ethical questions that health professionals face on a daily basis. However, philosophical thought experiments like this sometimes help to clarify questions that are of much broader relevance. In this case, the prospect of an all-female planet focuses our attention on what it means to be normal or abnormal, on the nature and implications of the different behaviour of men and women, on the political ramifications and resonances of bioethical debate, and on our obligations to future generations.

The possibility of an all-female world has featured in recent debates about enhancement-the use of medical technologies to enhance the capacities and characteristics of humans beyond what is considered normal. Philosopher Rob Sparrow has provocatively suggested that since females have a longer lifespan and are able to bear children, supporters of enhancement should support the deliberate selection of only female offspring. As this appears to lead to absurd conclusions, Sparrow has suggested that we should retain the therapy/enhancement distinction, embrace the difference between males and females, and reject the pressure to enhance members of our species.

Paula Casal's feature article in this issue (see page 722, Editor's choice) is a rebuttal of Rob Sparrow's reductio ad absurdum argument. Casal rejects all of Sparrow's conclusions. She argues that the therapy/enhancement distinction does not solve the problem that Sparrow has created. She also argues that we should work towards reducing sexual dimorphism, the phenotypic difference between sexes in our society. In one thought experiment, Casal imagines an imaginary, peaceful, egalitarian society (the island of
Equalia) populated by equal sized and equally long-living co-parenting couples. Casal argues that it is not clear whether working towards such a society would be therapy or enhancement, but that on either basis it would be worth pursuing.

Commentators on Casal's article pick up on different elements of the debate.

Larry Temkin (see page 729) reflects on common concerns about enhancements. He suggests that there is a kernel of truth at the heart of Sparrow's objections to enhancement: if we are to pursue enhancement we should do so cautiously, only after ensuring that "the ends we seek are truly desirable... that the means we adopt are fully permissible; and ... that the enhancements we would produce are genuine enhancements, all things considered".

Rob Sparrow, in his response to Casal (see page 732), focuses on one of Temkin's common concerns. He highlights the political danger of allowing broad social good to provide either a limit or a motivation for individual reproductive decision-making. Sparrow argues here, as he has elsewhere, that the 'new eugenics', focused on individual reproductive freedom, too easily slips into something that looks like the old eugenics. In particular, he contends that if concern about adverse social consequences is a reason not to select embryos of only one sex, concern about adverse social consequences could easily constrain a much broader range of reproductive decisions.

Jeff McMahan's response to Casal and Sparrow (see page 736) is characteristically insightful. He highlights the special 'impersonal' reasons that are at play when we are deciding between different hypothetical populations, for example one composed of a mixture of sexes, and another of only females. McMahan also examines Casal's suggestion that it would be good for humanity to move away from sexual dimorphism, through progressive weakening of certain distinctively (though not uniquely) male psychological traits. This could in theory be a problem intrinsically, instrumentally or impersonally. Ultimately, though, McMahan concludes that the impersonal or instrumental loss would be outweighed by a much greater gain, both for the individual and collectively.

Elsewhere in this issue, Michele Loi also enters into the debate about enhancement (see page 748 ), by identifying problems with the idea that 'normal function' provides a stable foundation for deciding which medical treatments ought to be publicly available. Although Loi's paper is not a response to Casal, he poses questions that could be applied to Casal's island of Equalia. Should medical treatments that would move us in the direction of Equalia be provided? Would our concept of normal function change?

Finally, one of the concerns about enhancement relates to a collective action problem-parents may make reproductive decisions that appear to be the best for their child and family, yet those same decisions if taken by all, may lead to significant collective harm. Jonny Anomaly (see page 752) looks at collective action problems and regulation of drugs. Anomaly argues that there is a stronger reason to regulate prescription of antibiotics than recreational drugs, and suggests a simple antibiotic tax as a partial solution. This then raises an interesting question: would the use of financial incentives and disincentives be preferable to the regulation/prohibition of enhancement and embryo selection?

\section{Competing interests None.}

Provenance and peer review Commissioned; internally peer reviewed. 